\title{
DYSLEXIA AND SELF-DEVELOPMENT; A PRODUCT FOR PRIMARY SCHOOL CLASSROOMS TO ENCOURAGE SOCIAL INTERACTION WITH THE INTENT OF IMPROVING SELF- ESTEEM.
}

\author{
Laschok, Zac Michael; \\ Lim, Younghun \\ Bournemouth University
}

\begin{abstract}
With an ever-increasing body of primary school children and the degradation of mental health among young people, the development of a high self-esteem at a primary school level has been recognised as a huge driving force towards the wellbeing of the next generation. Although the poor mental health of young people in their teenage years is widely talked about and addressed, it is often missed that this stems from a much younger age. The people most likely to suffer with a lower self-esteem at a young age are those with a learning differences, weather mild, diagnosed or undiagnosed. This paper will explore how emerging cognitive differences, and positive social interaction can help steer a child's self-development away from problems later in life such as anxiety and depression. Using these findings, a physical classroom-based game was conceived, designed and tested on the end users in the classroom environment.
\end{abstract}

Keywords: Education, phychosocial, Inclusive design, Human behaviour in design, User centred design

\author{
Contact: \\ Laschok, Zac Michael \\ Bournemouth University \\ Design and Engineering \\ United Kingdom \\ zmlaschok@gmail.com
}

Cite this article: Laschok, Z. M., Lim, Y. (2021) 'Dyslexia and Self-Development; A Product for Primary School

Classrooms to Encourage Social Interaction with the Intent of Improving Self-Esteem.', in Proceedings of the International Conference on Engineering Design (ICED21), Gothenburg, Sweden, 16-20 August 2021. DOI:10.1017/ pds.2021.132 


\section{INTRODUCTION}

As of 2019 there are 4.73 million children in primary schools across the UK, compared to 3.9 million 10 years ago, that's a 19\% increase in the primary school student body (Department of Education). This dramatic increase in students, combined with a decrease in education spending respectively (Nuffield Foundation), and new teachers entering the profession, has led to a noticeable overcrowding in schools, thus class sizes. The increased size in classes has meant significantly less one to one student - teacher time making it easier for children to go 'under the radar' when progressing through school (Ofsted, 2014). The term 'under the radar' refers to pupils who do not get sufficient attention for their inadequate academic ability and self-development. Research has shown the pupils most likely to fall into this category are those with undiagnosed mild dyslexia, learning difficulties or having a general low selfesteem due to environmental factors of school (Devonshire, M., 2014.). This is just one factor in the academic struggle for children with learning difficulties, the emergence of cognitive distinction among peers also plays a huge role in their attitude towards learning. Slow learners often become stigmatised and associated with failure, which in turn lowers their self-esteem further. The academic failure they experience becomes a constant source of frustration, for example knocking their confidence, self-worth and Self-advocacy. In the long term this can cause profound problems in their educational, personal and social life leading to anxiety, depression, and in some of the worst cases, suicide. There are said to be over 870,000 children in UK primary schools who have been diagnosed with Dyslexia, but due to expensive screening and symptoms often being too mild to be observed at younger ages, an estimated $80 \%$ of children are left undiagnosed (Department of Education 2019), this is roughly 700,000 children. Putting approximately 20 pupils with an undiagnosed learning difficulty per primary school across the UK. A learning difficulty is a neurological disorder that affects the brain's ability to receive, process, store and respond to information. Visual Processing Disorder and Dyslexia

are learning difficulties that cause problems with memory, reading, math, maps, charts, symbols and pictures. Children in school with learning difficulty struggle with social acceptance among their peers (Ryan, M., 2004), these students learn to internalise their problems due to the repetition of academic failure and this internalisation feeds into the low educational self-perception and learned helplessness. Non-verbal communication plays a major role in boosting a child with a learning difference selfesteem (lamer, S. et al. 2014). Positive communication can break down emotional and social barriers, and engagement with peers that results in a sense of achievement can reinforce a positive selfperception (Hall, C. et al. 1985). Tackling this problem from a design point of view will require a product to increase a child's self-esteem, something that is intangible and near impossible to track. The product will need to encourage the strategies and techniques proven by research that increase selfesteem, but do so within a classroom environment, in a method that children are motivated and enthusiastic to engage in. Some technical challenges include durability, sustainability, materials and manufacture, costing within a set budget that schools can afford but in a compact, easy to use form. Some humanistic challenges include, designing a task/ interaction that is engaging for the user while reducing the frustration felt in a social learning environment, designing an interface appropriate for the users age, and for the environment in which it is used, and awareness of how information exchange allows the emergence of cognitive distinction between users and how this will affect user's emotions. Currently there are no commercial products on the market specifically designed to improve self-esteem for children with dyslexia in learning environments, however there are some products that can be tweaked to improve self-worth and confidence that could potentially be used in schools, products such as Jenga Therapy and The Empowerment Cards Game. Most commonly used in schools are techniques or therapy, as well as games such as 'Toss the Compliment' that involves throwing a small bean bag around followed by a compliment to the recipient. The design solution is named 'KMKY', is a primary school classroom based physical activity game, designed to help children improve their self-esteem. Through forming and giving individual options, it gives children the opportunity to let their peers know who they are and discover common interests. The aim of the game is to collect as many disks as possible, these are won when a player succeeds in getting the ball in the goal and answering a question, also through active participation. With the help of primary school teachers, SENCo's, adults with dyslexia and a child development psychologist, a set of playful questions have been developed to help draw out opinions and provoke wonderment. 


\section{DESIGN PROCESS: DESIGNING AN EDUCATIONAL TOY}

The adopted design process (methodological framework) reflects the qualitative approach using several empirical studies. To conduct effective empirical studies, a breadth of knowledge was needed on the neurological disorder itself and child development in general. A wide range of the existing literature around Dyslexia and the negative psychological effects it has on the sufferers was thoroughy reviewed. Understanding the gaps and discrepancies in the currently literature became key to drafting the questions that needed answering in the later stage i.e. primary research. In order to achieve the greatest possible validity of the data from the primary research, the research triangulation (Robson \& McCartan, 2016) was adopted along with the human-centred design methods. The chosen design research methods are series of the expert interviews, focus group discussion with the groups of designers, and test analysis with the potential users.

\subsection{Data collection and analysis}

As the first data collection method, a series of interviews with people that have comprehensive experiences and understanding of children and or Dyslexia was conducted. The in-depth semistructured interviews with the primary school teachers and psychologists in Dyslexia were firstly conducted by the lead researcher. The aim of the first round of the interviews was to confirm the findings from the literature but also identify any information that were no identified from the literature. The initial design concepts were also shared at the end of the interview in order to identify the design aspects that were not considered to be in the design criteria. Key findings being features such as a motive to participate, environmental factors and user comprehension. It was vital that time in a primary school was spent. Fortunately, this was granted along with interviews with a Year 4 teacher and Year 6 teacher with governor status at the school, both having over 5 years' experience. Their experience with the affected children, and overall explanation of the social dynamics in primary schools gave great insight into how schools implement new products or techniques. These participants also offered to watch out for trends among the types of students discussed in the authors research, to then feedback to the author in a second interview. To broaden the research further, the author conducted interviews with Special Educational Needs Coordinators (SENco's) in different primary schools. This gave a more in-depth understanding of the measures currently in place in school for the affected children. One of the participants having been a classroom teacher for carious year groups prior to becoming a SENCo, this furthered the authors understanding of the user dramatically and validated the concept. Analysis of interviews was done using a first cycle 'generic' coding method (Saldaña, 2015). This pointed out similarities, frequency, sequences and causation in conversation. Being able to visualise this made it easy for the author to pick out important features mentioned and trends across participants' information. A focus group discussion was conducted with 25 product designers to develop the initial design specification such as shape, material, size etc. All the discussions were recorded and also analysed using the above coding analysis method. Finally, the developed prototype was tested at school with four children 8-9 years old. Due to the limitation of the Ethical approval, the test was led by the schoolteacher without the researcher's presentation. The feedbacks from the children were also provided by the schoolteacher.

\subsection{Development and evaluation}

Having spent a considerable amount of time of the concept and detail design phase in various schools discussing development with relevant experts, a sound level of confidence was given that the concept met the preferences, and requirement of the end user. Taking into account cognitive processes, motivations of engagement and environmental criteria, such as durability and lifespan. 


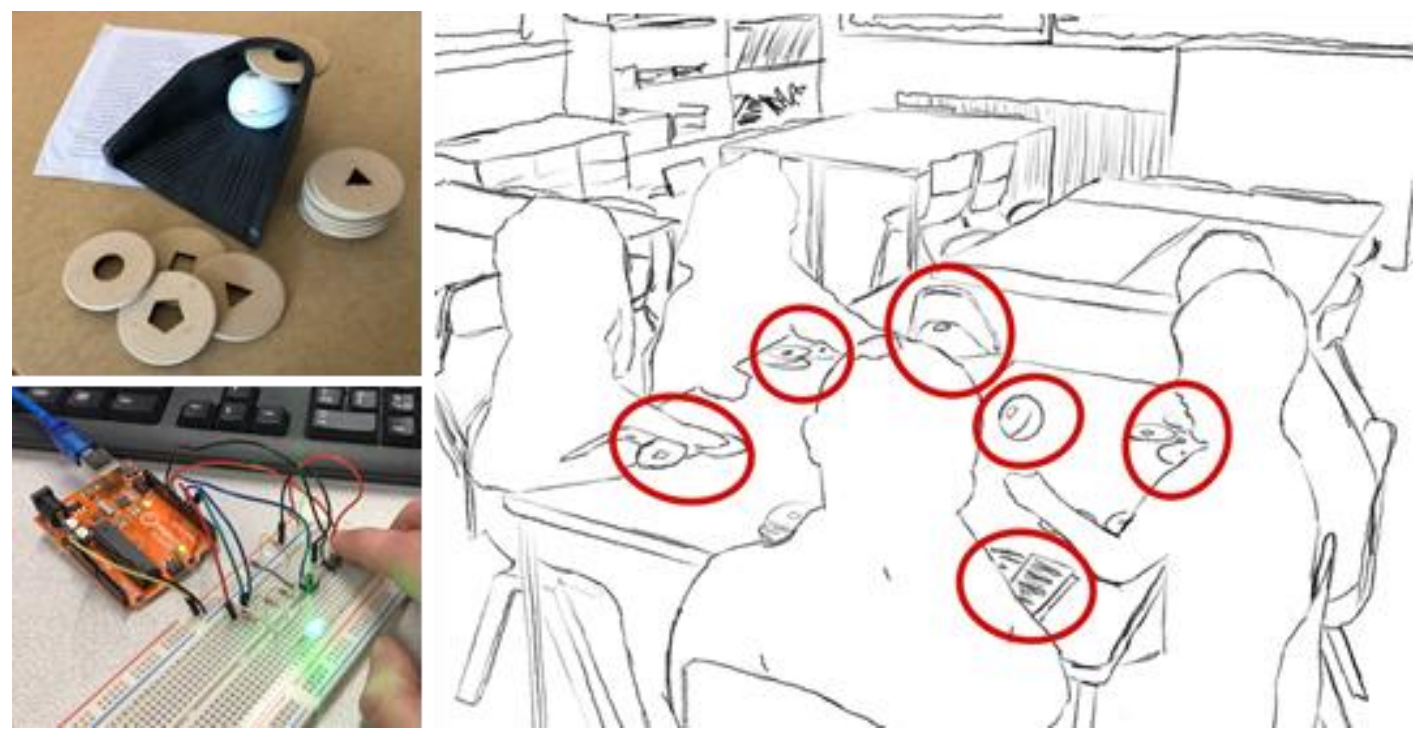

Figure 1. Sketch of what tests looked like, Author

The final concept was derived from the discussion activities that increase self-esteem, into a game with a reward system of collecting disks. An activity of rolling a ball into a goal was chosen from an activity matrix of possible activities that could be performed in a classroom. This gives the product a small physical challenge to maintain engagement. Some changes in the flow of the game included a swap from the players offering up tokens to get rid of and players now wanting to win the tokens from the accompanying adult. Once a semi working prototype was made, the author tested the game with 4 children in a primary school. The first half of the test involved the pupils rolling the ball into the goal from different distances, also putting the disks in the slot. All the participants (4) found this task fun and engaging, being eager to have another go. The second half of the test got the accompanying teacher asking pupils a selection of questions from the game. The pupils were very engaged in expressing their opinions with each other, although not being considered friends or 'likely to play with each other at break and lunch'. The feedback from this test suggested to the author that, the product succeeds in its intent to encourage users to form and give options, while maintaining focus throughout.

\section{JUSTIFICATION \& FINAL DESIGN SOLUTION}

\subsection{Performance \& Function}

Studies have shown positive communication as an effective method to increase a child's self-esteem (Calsyn et al, 1980). Forming and giving opinions in a judgement free environment has also been said to be one of the most effective methods in developing one's personality (Harris, 1995, Rubin \& Wilkinson, 1995 and, Rutland et al, 2012). These theories, coupled with a sense of achievement when interacting with other children, are the foundations of the product's function. The product aims to open up such an environment for users to communicate in this way. The game has been designed in its entirety to subconsciously develop the user's self-esteem within the learning environment. A sense of achievement during social situations has been proven to aid in a child's self-development (Green et al., 1980). The product allows users to build on others opinions, provoking the discovery of common interests. The knock-on effect of this process leads to stronger bonds between users or even the blossoming of new relationships. To fulfil this, the product encourages users to participate in order to 'win' the game. With questions designed around the average activities and interest of 7-10-year-old children. The product consists of a light up ball that acts as a dice to pick the topic of question, a goal to roll the ball into to 'win' the chance to be asked a question, and different shaped disk tokens that the users want to collect in order to 'win'. The ball is randomised to further keep users engaged as predictability can become boring in games (Tominey \& McClelland, 2011). Testing proved the act of rolling the ball in the goal to be an engaging task, requiring a moderate amount of skill that can be improved over time. This task also acts to capture and maintain attention throughout the game, as every player during the test was eager and waiting to take another go. 


\subsection{Ergonomics}

Considerable amounts of care were put into the user trip to ensure no unnecessary processes were encountered. Theories of 'game- flow' (Che, 2007) have been followed in design of the games working. This theory looks at what operation follows user inputs and how much thought needs to go into participating in games. Anthropometrics were considered as well as a mix of phycological, motor and cognitive abilities. Standards such as ISO/TR 81278:2014 were followed to ensure the product solution would cause no harm to the user and that it would be viable for sale in the UK.

\subsection{Anthropometrics}

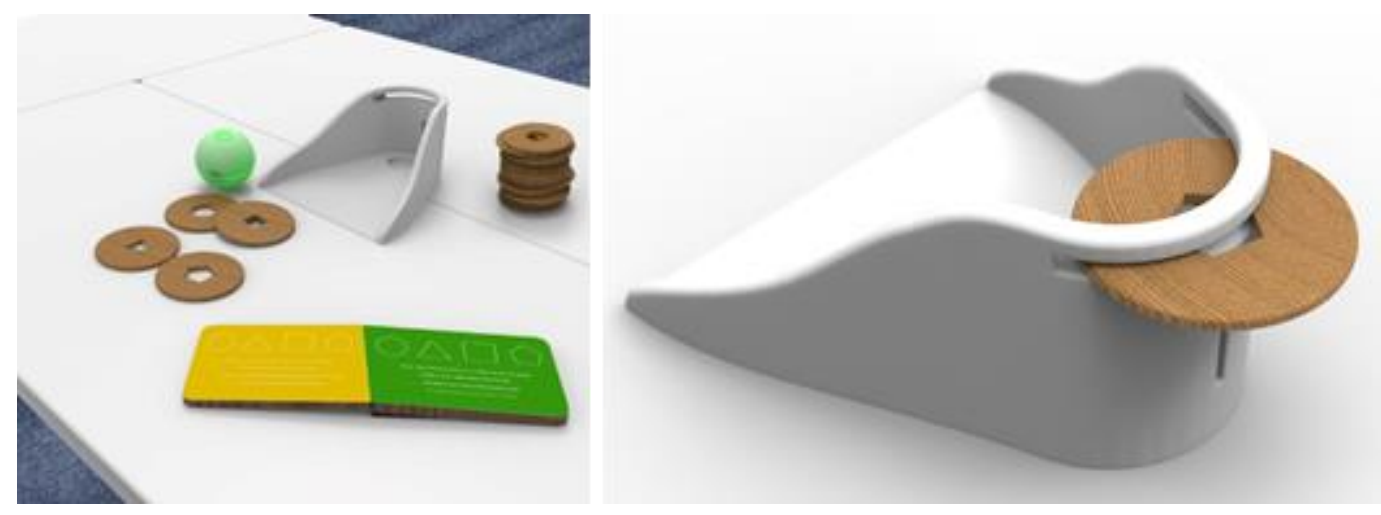

Figure 2. Final design concept

KMKY is designed for the average dexterity of 7-10-year old's, using the 50th percentile of 8-year-old boys and girls hand width, length and grip size for the ball and disks (Pheasant, 2003). As well as researching various children's toys currently on the market, the appropriate size for the ball was seen to be 70 millimetres. Taking away any unergonomic factors makes certain the game flow to be effortless and enjoyable. This incorporates the button size and pressure needed to operate. The same goes for the disks, being reversible and non-directional, this takes away any unnecessary thought process making them easy to slot in the goal. Testing with the end users (8-9-year-old's) highlighted no issues when putting the disks in. KMKY's goal opening is more than wide enough for accurate rolling of 1 meter away. This was proven in testing in a primary school, allowing children of 8 and 9 to roll the ball in from up to 2 meters away. The weight of the ball is 50 grams, well within the lifting ability of children ages 7-10 (Pheasant, 2003). The button requires no more than 1.5 newtons of force to operate (Button data sheet $+10 \%)$.

\subsection{Clarity of information}

Designing for child users, intuitive design language has been used. Little to no symbols and text have been used as to not hinder usability. The only language used in the product are basic shapes, being understandable to the intended users (Department for Education, 2013). The intended users being children with various forms of Dyslexia, any unrecognisable symbols would take away from the pleasure of using the product, as the affected can struggle with symbol recognition (Muter \& Snowling, 2009). The design language of the goal provides the user with a clear 'goal' of what the task involves, bridging the gulf of execution is down to the user interpretation. The unobtrusive design also provides clear instruction of where to put the disk tokens. The accompanying adult can tell straight away what question is needed to be asked by visually combining the colour and shape on that users turn.

\subsection{Cognitive Function}

Observations from primary schools validated stage 3 of 'Piaget's theory of cognitive development' (1937), revealing that the concentration of young children to be that of around 10-minute fragments. KMKY's flashing ball and ball rolling activity helps to maintain attention throughout the game by providing the user with a source of mild physical entertainment. Questions are designed to provoke thoughts of external environments and form personal opinions which (Green, 1980) has shown to be essential in developing a positive self-perception. 


\subsection{Motor control}

As children of this age are still developing their fine motor skills it was apparent that testing with the end user was vital. Upon testing the product with the end users, the task of getting the ball in the goal proved to be highly achievable, while still requiring moderate skill to do so. Feedback from the accompanying teacher confirmed this also observing no struggle when it came to putting the disks in the goal.

\subsection{Psychological Development}

The aim of KMKY is to improve self-esteem in the learning environment. The authors research findings revealed that the following experiences have been proven to help improve self-esteem for children of all ages; Positive feedback (Phillips et al, 2008) Giving opinions (El Keshky \& Samak, 2017) Identifying strengths (Myers et al, 2011) Social interaction/ feeling of acceptance (Harris \& Orth, 2019) Feeling of value (Kernis, 2005) These methods have been woven into KMKY through the use of questions. The game itself provides a judgment free space in which to perform the methods while not making the users feel as though the purpose of the exercise is to perform the self-esteem improvement methods intended.

\subsection{Aesthetics}

It was important for KMKY's form to be portrayed as playful but also embedded within its form, obvious goal signifiers. This was achieved with the use of interesting curves, natural materials, and vibrant coloured lights. According to Lidwell (et al, 2010), humans are naturally drawn to rounded shapes, using this principle along with practical and safety requirements for the goal and tokens, little sharp edges were given to the product. The foundation of the goals form come from its ability to receive the ball and hold it in place. The curves of the walls were then sculpted as to direct the light out the front of the goal, a small slit on the back also lets the light pass through in case the goal is facing away from the accompanying adult. Smooth curves aim to give it a natural feel, in conjunction with the natural material used.

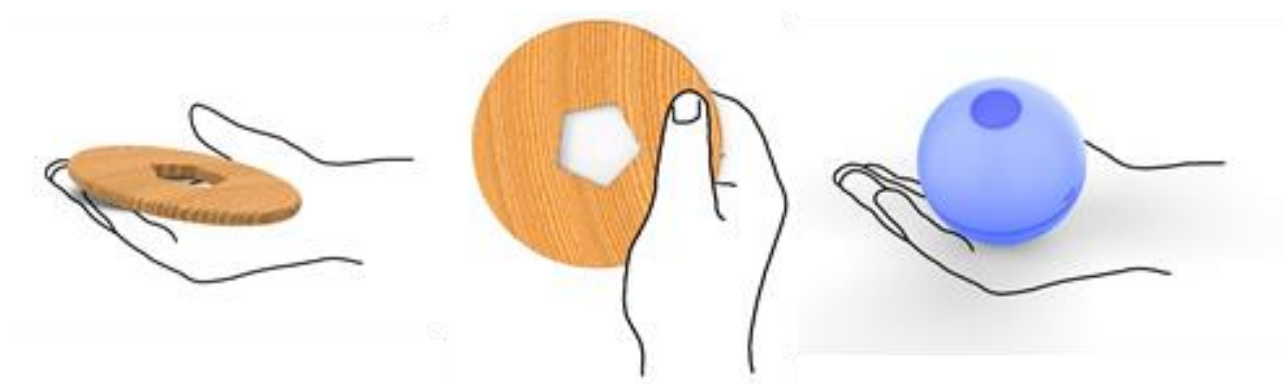

Figure 3. Illustration of size of disks and ball with the potential users' hand

\subsection{Materials}

Material selection was primarily driven by adhering to high durability standards (EN 71-1: 2014+ A1:2018). The part of the product most susceptible to damage is the ball, therefore it is made from High Density Polyethylene for its exceptional strength to weight ratio. Lightweight properties being needed for safety and ergonomic reasons. All parts of the ball needing a translucent finish can be achieved with HDPE, with the desired matte texture finish also. This material has appropriate chemical resistant properties which, in the current climate of 2020, will become necessary for frequent cleaning due to the product being passed around multiple users. Utilisation of natural materials became important through research. Findings exposed the psychological calming effects of natural materials such as wood (Rice et al. 2006). This would also decrease the product's carbon footprint and increase its sustainability (if sourced correctly). A focus group run by the author looking at the different textures of wood revealed Oak to be the most pleasurable. The texture of the button needed to differ from the rest of the ball so the users would be able to identify it easily. For this silicone was used for its elastic properties also meant the button could be flush with the rest of the ball as to not affect its roll. 


\subsection{Manufacture}

All parts of the ball are to be injection moulded from HDPE as the high quantities make this highly cost efficient. This method can also achieve the small details required to a high degree of accuracy. The internals of the ball are designed in a sandwich-like structure for durability. The two sides of the sphere will be glued to the cereal support using a clear, low viscosity bio-derived epoxy resin. The goal will be made by compression moulding HDPE, post processing will see the slit for the disks and light to travel though on the back. As the goal is much larger and a single piece, compression moulding was seen as most appropriate due to the thickness of part, that could not be achieved via injection moulding. There is also very little waste compared to injection moulding. The disks will be laser cut from $6 \mathrm{~mm}$ thick FSC certified Oak. Post process will see the chamfer around the outer edge of the disk and sanding to a smooth finish.
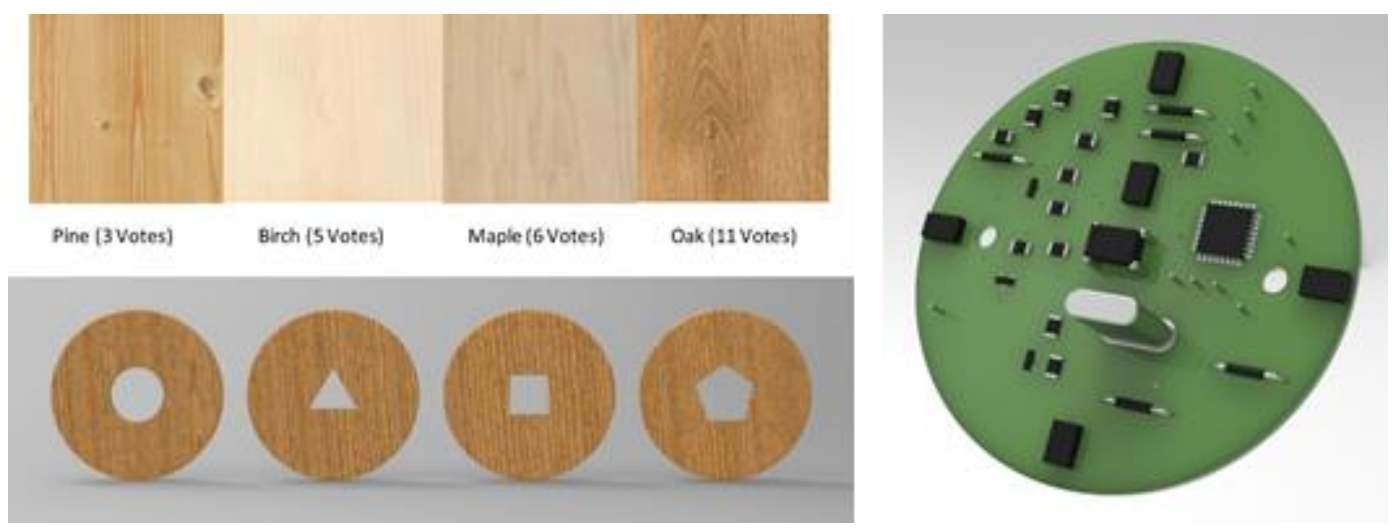

Figure 4. Illustration of the material of disks and $3 D C A D$ rendered $P C B$ board

\subsection{Safety}

As the product is intended to be used by children, British toy safety standards and EN17 were adhered to during the design process. There are no sharp edges on any part of the product, no toxic or harmful substances or materials have been used and all electronics are housed inside a sealed unit. The battery only outputs a maximum of 3.7 volts as to not cause harm if it was to come into contact with a user. Careful consideration was given to the durability of parts. Appropriate materials were selected to ensure no parts will not crack during the products life in service. Measures have also been taken to ensure no electronic components will accessible. Instructions for use will be included in the product, highlighting any potential hazards and its age suitability.

\subsection{Maintenance \& Disposal}

The product has been designed to require no maintenance over its lifespan, with the batteries being rechargeable and a life spanning over 5 years. The LED's life also being over 5 years, there is no need for the user to dissemble the ball. The goal and disks have no moving parts, there is no maintenance needed apart from cleaning when felt necessary. HDPE being highly chemical resistant, even frequent cleaning will not deteriorate the product's parts. Oak being a very dense material, means there will be little to no cracks for dirt to sit. Storage would ideally be in a cool dry cupboard in the products box, see figure $\mathrm{xx}$. The product has not been awarded an IPX rating therefore the ball containing the electronics should not be submerged in water. Due to the product involving separate parts, recycling of over $90 \%$ of the product is made easy. The Oak disks can be recycled and used for compost or mulch, they can also be turned into particleboard or chipboard lumber. The solid HDPE goal and some parts of the ball can be shredded and melted down, then cooled into pellets which can be used again in manufacturing.

\subsection{Professional Issues}

Copyright will prevent separate parties using the authors creative endeavours for the period of protection, the author's lifetime plus another 75 years. It does not protect the idea, but the way the concept is conveyed. It is feasible to obtain copyright for illustrative works as part of KMKY. Any 
works produced would benefit from attaching the copyright symbol ' $(\mathrm{C}$ '. Medium such as drawings, renders, coding, illustrations and any other graphical works produced will be protected by copyright when created.

\section{DIscussion}

Primary research (expert interviews and user test) confronted initial presumptions found through secondary research, constantly moving the design challenge to ensure a valid design solution. The humanistic challenge matured throughout the design and research process, the utilisation of game principles with social interaction, while maintaining attention, emerged early on. Overcoming the obstacles involved for the product to be viewed by customers not just as a game, but an aid in social development proven difficult, but the evidence through testing and customer feedback proved these methods effective alongside the products main function. Testing proved the game itself to be fun and entertaining while opening the users mind, giving opinions to one another, an effective method for developing personality and increasing self-esteem (Rutland et al, 2012; Harris, 1995; Rubin \& Wilkinson, 1995). Where the design criteria are to encourage users to give opinions, it was vital a solid foundation of research backing methods on how to do this was acquired. Evaluation from teachers was that the game got the pupils talking, even saying they learned things about the kids that they had previously not known. Based on secondary research, testing and feedback, KMKY is theoretically practical and feasible. This can be shown by the test conducted with the group of year four children that have either been diagnosed, or are suspected to suffer with Dyslexia, these pupils' characteristics were also described by their teachers as shy and not being a usual group to interact with one another. The test succeeded in getting this group to interact on various social levels including post-test socialising in class therefore possibly leading to a higher self-esteem (Calsyn et al, 1980 and, Green, 1980). The author has adhered to the ethics laid out in the ethics checklist completed at the beginning of the project. In-depth research into an end user group i.e. children, required primary research to be carefully planned with appropriate amendments made to the institutional ethics checklist when required, then followed strictly. The product will be manufactured and assembled in China due to the availability of manufacturing techniques being highly cost effective. Therefore, the author will ensure factory profiles are considered, including appropriate employee wages, treatment or any other unethical practice, when selecting manufactures. Frequent visits will be made to factories to ensure this prior to any mass manufacture runs or ordering of parts.

\subsection{Short Term Design Improvements}

Development is never concluded, only done so by recommended stages due to the time constraints of the project. Some of the improvements that can clearly be made to the product include a swivel function to the goal or ability to roll the ball in without having to physically move the part. A reduced price would make the products more accessible, opening up markets such as out of school clubs, scouts or girl guiding groups and summer camps. Future development would also see the use of threads or snap hooks to attach the spheres without jeopardising performance or life span. It would also see more of the components sourced from within the UK or Europe without increasing the end user cost. An IPX rating would also be sought in future development.

\subsection{Methodological limitation}

A total of 4 children were tested in the group test but this is not due to the limitation of sampling, the long-term effects cannot be tested without further research and monitoring of participants who have tested the product. This was not possible during the testing of the product due to an unforeseen global pandemic and the closure of schools at that time. Further limitations include that of evaluation due to the teachers interviews after the test were limited in knowledge regarding the neurological disorder and its influence on self-esteem. Furthermore, due to the ethical reasons, comparative monitoring of two samples, one group who had played the game and one who has not, could not be conducted. This comparison would show any progress users make therefore giving validation to the product. 


\section{CONCLUSION AND FUTURE WORKS}

\subsection{Summary}

There are approximately 20 pupils per primary school across the UK with a diagnosed or undiagnosed learning difficulty. These students very often have a low self-esteem due to a struggle with social acceptance, low educational self-perception and learned helplessness. Positive communication can break down social barriers, and engagement with peers' results in a sense of achievement which can reinforce a positive self-perception. KMKY is a classroom based educational toy designed for 7-10year-olds that aims to promote communication with peers. The target of this being to increase a pupils self-esteem which will enable the child to develop their personality and confidence, reducing the risk of anxiety, depression and suicide.

\subsection{Contribution to knowledge}

The contribution to knowledge of this research can be explained by its originality, significance, and rigour. Originality: There are limited products on the market specifically designed to improve selfesteem for children with dyslexia in learning environments. This project was focused in the context of primary school children who have been diagnosed with Dyslexia and also those who are suspected to have Dyslexia but have not yet been diagnosed. Both secondary and primary research outcomes argued that self-esteem is the key aspect to improve their learning on both individual and social level. With this in mind, the design of a physical game was proposed. Significance: It can be argued that the outcome of this project can play a significant role in developing and expanding the design of an educational toy for children with Dyslexia or other learning difficulty in both academic environments and in the toy or game design industry. Rigour: The project was thoroughly designed adapting several human-centred design tools such as stakeholder analysis, expert interview, user test. The proposed solution i.e. game was designed not only based on the cognitive and anthropometrical data but also the consideration of users' psychosocial aspects such as social interaction, feeling of acceptance, and cognitive process to increase the motivations of engagement.

\subsection{Future works}

A decreasing age of young people owning mobile devices would open the opportunity of the addition of an app to KMKY, adding the ability for users to add their own questions they would like to find out about their peers or taking questions home. This feature could also aid in the development of more questions and possibly develop a more specialised version of the game to include children with more severe learning difficulties. Development for versions of the game for more severely affected children could include features such as the option of thinking about answers prior to starting a game, in order to take pressure off users.

\section{REFERENCES}

Belfiels, C. Farquharson, C. Sibieta, L., 2018. 2018 Annual Report on Education Spending in England [online]. Institute for Fiscal Studies.

Che, J. 2007. Flow in games (and everything else), Communications of the ACM

Cheti Nicoletti of the Department of Economics 2010. Spending it wisely: How can schools use their resources to help poorer pupils? Nuffield Foundation.

Department for Education, 2013. The national curriculum in England Key stages 1 and 2 framework document

Department of Education, 2019. Schools, pupils and their characteristics: January 2019 [online]. Department of Education.

Devonshire, M., 2014. Children with dyspraxia are falling 'under the radar' and missing out on vital support in schools [online]. Dyspraxia Foundation.

Eco resin glue - https://www.adhesivesmag.com/articles/88268-biodegradable-polymers-in-adhesive- system

El-Keshky, Mogeda \& Samak, Yasser. (2017). The Development of Self Esteem in Children: Systematic Review and Meta-Analysis. International Journal of Psychology \& Behavior Analysis. 3. 10.15344/24553867/2017/128.

Green, Kenneth D., Rex Forehand, Steven J. Beck, and Barbara Vosk. "An Assessment of the Relationship among Measures of Children's Social Competence and Children's Academic Achievement." Child Development 51, no. 4 (1980): 1149-156. Accessed May 29, 2020. https://dx.doi.org/10.2307/1129556. 
Hall, C. W., \& Richmond, B. O. 1985. Non-verbal communication, self-esteem and interpersonal relations of LD and non-LD students. Exceptional Child, 32(2), 87-91.

Harris, J. R. (1995). Where is the child's environment? A group socialization theory of development. Psychological Review, 102(3), 458-489. https://doi.org/10.1037/0033-295X.102.3.45

Harris, M. A., \& Orth, U. (2019, September 26). The Link Between Self-Esteem and Social Relationships: A Meta-Analysis of Longitudinal Studies. Journal of Personality and Social Psychology. Advance online publication. http://dx.doi.org/10.1037/pspp0000265 https://www.wipo.int/classifications/nice/nclpub/en/fr/? class_number=41\&explanatory_notes=show\&lang=en \&menulang=en\&notion=class_headings\&version=20 190101

Jennifer Stephenson (2007) The effect of color on the recognition and use of line drawings by children with severe intellectual disabilities, Augmentative and Alternative Communication, 23:1, 44-55, https://dx.doi.org/10.1080/07434610600924457

Johnson, H. Carroll, J. \& Bradley, L., 2017. SEN support: a survey of schools and colleges [online]. Coventry: Coventry University

Kernis, M.H. (2005), Measuring Self-Esteem in Context: The Importance of Stability of Self-Esteem in Psychological Functioning. Journal of Personality, 73: 1569-1605. https://dx.doi.org/10.1111/j.14676494.2005.00359.x

Lamer, S. Reeves, S. Weisbuch, M., 2015. The nonverbal environment of self-esteem: Interactive effects of facial-expression and eye-gaze on perceivers' self-evaluations. Journal of Experimental Social Psychology. 56. 130-138. 10.1016.

Lidwell, W., Holden, K., Butler, J., \& Elam, K. (2010). Universal principles of design: 125 ways to enhance usability, influence perception, increase appeal, make better design decisions, and teach through design.

Lydia Alexandra Heinrich, 2019. Future opportunities for bio-based adhesives - advantages beyond renewability. Green chemistry issue 8 .

Mihaly Csikszentmihalyi Flow: The Psychology of Optimal Experience (2008), by, published by Harper Perennial Modern Classics

Muter, V. and Snowling, M.J. (2009), Children at Familial Risk of Dyslexia: Practical Implications from an AtRisk Study. Child and Adolescent Mental Health, 14: 37-41. https://dx.doi.org/10.1111/j.14753588.2007.00480.x

Myers, J.E., Willse, J.T. and Villalba, J.A. (2011), Promoting Self-Esteem in Adolescents: The Influence of Wellness Factors. Journal of Counseling \& Development, 89: 28-36. https://dx.doi.org/10.1002/j.1556678.2011.tb00058.x

O'Donnell, A. (Ed.), King, A. (Ed.). (1999). Cognitive Perspectives on Peer Learning. New York: Routledge, https://doi.org/10.4324/9781410603715

Ofsted, 2014. Below the radar: low-level disruption in the country's classrooms [online]. Ofsted. Phillips, D., Hagan, T., Bodfield, E., Woodthorpe, K. and Grimsley, M. (2008), Exploring the impact of group work and mentoring for multiple heritage children's self-esteem, well-being and behaviour. Health \& Social Care in the Community, 16: 310-321. https://dx.doi.org/10.1111/j.1365-2524.2008.00761.x

Qualitative data coding manual

Robert J. Calsyn, Jan Quicke and Sharon Harris do improved communication skills lead to increased selfesteem? Elementary School Guidance \& Counseling Vol. 15, No. 1 (October 1980), pp. 48-55 Robson, C., \& McCartan, K. (2016). Real world research. John Wiley \& Sons.

Rubin K.H., Wilkinson M. (1995) Peer Rejection and Social Isolation in Childhood: A Conceptually Inspired Research Agenda for Children with Craniofacial Handicaps. In: Eder R.A. (eds) Craniofacial Anomalies. Springer, New York, NY

Rutland, A., Cameron, L., Jugert, P., Nigbur, D., Brown, R., Watters, C., Hossain, R., Landau, A. and Le Touze, D. (2012), Group identity and peer relations: A longitudinal study of group identity, perceived peer acceptance, and friendships amongst ethnic minority English children. British Journal of Developmental Psychology, 30: 283-302. https://dx.doi.org/10.1111/j.2044-835X.2011.02040.x

Ryan, M. \& International Dyslexia Association., 2004. Social and Emotional Problems Related to Dyslexia [online]. http://www.ldonline.org

Saldaña, J. (2015). The coding manual for qualitative researchers (No. 14). Sage.

Shauna L. Tominey \& Megan M. McClelland (2011) Red Light, Purple Light: Findings From a Randomized Trial Using Circle Time Games to Improve Behavioral Self-Regulation in Preschool, Early Education and Development, 22:3, 489-519, https://dx.doi.org/10.1080/10409289.2011.574258

Stephen Pheasant, 2003. Bodyspace: Anthropometry, Ergonomics, and the Design of Work. Taylor \& Francis

UK Government, 2020. How Copyright Protects Your Work [online]. https://www.gov.uk/copyright Volume 50, Number 4 (2007), Pages 31-34 WIPO IP Portal, 2020. 